\title{
NAO and extreme ocean states in the Northeast Atlantic Ocean
}

\author{
Emily Gleeson $^{1}$, Sarah Gallagher ${ }^{1}$, Colm Clancy $^{1}$, and Frédéric Dias ${ }^{2,3}$ \\ ${ }^{1}$ Research, Environment and Applications Division, Met Éireann, Dublin, Ireland \\ ${ }^{2}$ School of Mathematics and Statistics, University College Dublin, Ireland \\ ${ }^{3}$ CMLA, ENS Cachan, CNRS, Université Paris-Saclay, 94235 Cachan, France \\ Correspondence to: Emily Gleeson (emily.gleeson@met.ie)
}

Received: 12 December 2016 - Revised: 3 February 2017 - Accepted: 6 February 2017 - Published: 10 February 2017

\begin{abstract}
Large scale atmospheric oscillations are known to have an influence on waves in the North Atlantic. In quantifying how the wave and wind climate of this region may change towards the end of the century due to climate change, it is useful to investigate the influence of large scale oscillations using indices such as the North Atlantic Oscillation (NAO: fluctuations in the difference between the Icelandic low pressure system and the Azore high pressure system). In this study a statistical analysis of the station-based NAO index was carried out using an ensemble of EC-Earth global climate simulations, where EC-Earth is a European-developed atmosphere ocean sea-ice coupled climate model. The NAO index was compared to observations and to projected changes in the index by the end of the century under the RCP4.5 and RCP8.5 forcing scenarios. In addition, an ensemble of EC-Earth driven WAVEWATCH III wave model projections over the North Atlantic was analysed to determine the correlations between the NAO and significant wave height $\left(H_{\mathrm{s}}\right)$ and the NAO and extreme ocean states. For the most part, no statistically significant differences were found between the distributions of observed and modelled station-based NAO or in projected distributions of the NAO.

Means and extremes of $H_{\mathrm{S}}$ are projected to decrease on average by the end of this century. The 95th percentile of $H_{\mathrm{s}}$ is strongly positively correlated to the NAO. Projections of $H_{\mathrm{s}}$ extremes are location dependent and in fact, under the influence of positive NAO the 20-year return levels of $H_{\mathrm{S}}$ were found to be amplified in some regions. However, it is important to note that the projected decreases in the 95th percentile of $H_{\mathrm{s}}$ off the west coast of Ireland are not statistically significant in one of the RCP4.5 and one of the RCP8.5 simulations (me41, me83) which indicates that there is still uncertainty in the projections of higher percentiles.
\end{abstract}

\section{Introduction}

The Northeast Atlantic possesses an energetic and variable wind and wave climate which has a large potential for renewable energy extraction; for example along the western seaboards off Ireland as discussed in Gallagher et al. (2013, 2016c) and Atan et al. (2016). The role of surface winds in the generation of ocean waves means that global atmospheric circulation patterns and wave climate characteristics are inherently connected. Several studies have identified strong correlations between the Atlantic wave climate and teleconnections such as the North Atlantic Oscillation (NAO) and the East Atlantic teleconnection pattern (EA) (Barnston and Livezey, 1987); both at Atlantic basin scale (Wang and Swail,
2001, 2002) and for the Northeast Atlantic region (Charles et al., 2012; Bertin et al., 2013; Dodet et al., 2010; Atan et al., 2016; Santo et al., 2016a). Le Cozannet et al. (2011) carried out a regional study using the ERA-40 dataset (Uppala et al., 2005) to drive the WAve Model (WAM) for the Bay/Gulf of Biscay (west of France) and also found a strong influence of the NAO/EA on the wave climatology in that region. The East Atlantic Western Russian (EAWR) pattern and the Scandinavian pattern are other modes of Northern Hemisphere atmospheric variability, and along with the EA have a weaker influence on the North Atlantic than the NAO (Santo et al., 2016b). For the purpose of the study presented in this paper, we focus on the NAO which is the most important North- 
ern Hemisphere mode of variability (Greatbatch, 2000; van Loon and Rogers, 1978; Hurrell, 1996). In addition, it is associated with changes to the westerly winds across the Atlantic and hence to the wave climate. In particular, variations in its amplitude and phase manifest themselves in changes to the frequency and intensity of blocking patterns and the position and intensity of the Atlantic storm track (Scherrer et al., 2006). During the positive phase of the NAO the pressure gradient over the North Atlantic increases due to strengthening of the Icelandic Low and Azores High. Stronger westerly winds, associated with the increased pressure gradient, also generate larger waves. On the contrary, a negative NAO phase is associated with a weaker pressure gradient over the North Atlantic and slacker westerly winds.

The NAO index is sensitive to the method used in its definition. It is most commonly defined as the difference between mean sea-level pressure (MSLP) anomalies in the Icelandic Low and Azores High action regions. Stykkisholmur, Reykavik or Akureyri (all in Iceland) are commonly used for the specific locations in the Icelandic Low and Ponta Delgada (Azores), Lisbon (Portugal) or Gibraltar for the Azores High (Hurrell, 1996; Pokorná and Huth, 2015). The stationbased NAO index can thus be calculated using station observations or gridded reanalysis datasets (using the nearest grid point to the location of interest or some weighted average). In the case of the latter, $500 \mathrm{hPa}$ geopotential height is also often used in place of MSLP. As well as basing the index on fixed locations, it can also be defined using the location of the centres of both pressure regions (Icelandic Low and Azores High), which change with time (Hameed and Piontkovski, 2004). An alternative approach for the calculation of the index involves principle component analysis (PCA). Gridded, rather than station, data are required where either MSLP or $500 \mathrm{hPa}$ geopotential height may be employed. A PCA of the leading Empirical Orthogonal Function (EOF) of MSLP $/ 500 \mathrm{hPa}$ height anomalies over the North Atlantic region spanning $20-80^{\circ} \mathrm{N}$ and $90^{\circ} \mathrm{W}-40^{\circ} \mathrm{E}$ is used to calculate the NAO time-series. Either correlation or covariance matrices can be used with this method and the EOFs may or may not be rotated. The PCA method is particularly sensitive to the spatial domain and time period used. Dommenget and Latif (2002) showed that patterns derived from EOFs may be misleading at times and not associated with climate physics.

Gallagher et al. (2014) identified a strong link between the station-derived NAO and significant wave height $\left(H_{\mathrm{s}}\right)$, wave period and peak direction for winter and spring off the west coast of Ireland where WAVEWATCH III (Tolman, 2014), driven by ERA-Interim data, was used to derive the wave climatology. The influence of the EA, while significant, was much smaller, and mostly affected waves off the southern half of Ireland in autumn and winter. In a separate study Gallagher et al. (2016a, b) showed that an EC-Earth (Hazeleger et al., 2010, 2012) driven WAVEWATCH III ensemble of wave projections indicates an overall decrease in the mean and 95th percentile of $H_{\mathrm{s}}$ in summer and winter around Ire- land by the end of the 21 st century. Further details on the ECEarth global atmosphere/ocean/sea-ice coupled model and WAVEWATCH III spectral numerical wave model are provided in Sect. 2. The study presented here expands on Gallagher et al. (2014, 2016a, b) and focusses on the influence of the NAO on extreme sea states in the North Atlantic and how this may change in the future. This is important because phenomenal sea states $\left(H_{\mathrm{s}}>14 \mathrm{~m}\right)$ have been regularly reported off the west coast of Ireland (Tiron et al., 2015; Gleeson et al., 2013; Clancy et al., 2015, 2016; O’Brien et al., 2013).

It is important to point out that there is still considerable uncertainty in projected changes in the frequency and intensity of extratropical cyclones over the North Atlantic (Ulbrich et al., 2009; Woollings et al., 2012) which directly impacts on projections of the wave climate. As a result, there is also substantial uncertainty in projected changes to Northern Hemisphere winter storm tracks, especially in the North Atlantic basin (Church et al., 2013), as a result of factors including horizontal resolution (Colle et al., 2013), the Atlantic Meridional Overturning Circulation (Woollings et al., 2012) and the zonal jet and Hadley circulation (Zappa et al., 2013).

The paper is organised as follows: Sect. 2 provides details about the EC-Earth and WAVEWATCH III models used in this study and a summary of their validation is given in Sect. 3. In Sect. 4 the results are presented and discussed. We conclude the findings of this study in Sect. 5.

\section{Models and datasets}

The EC-Earth global climate model and WAVEWATCH III wave model were used to generate the atmospheric and wave datasets used in this study. A third datatset, the National Centre for Atmospheric Research (NCAR) NAO station-based time-series was also used. Details regarding the models and datasets are provided in this section.

The EC-Earth global climate model (version 2.3) used in this study consisted of an atmosphere-land surface module coupled to an ocean-sea ice module (Hazeleger et al., 2010, 2012). The atmospheric component of the model was based on the European Centre for Medium-Range Weather Forecasts (ECMWF) Integrated Forecasting System cycle 31r1 with T159L62 spectral resolution (corresponding to $1.125^{\circ}$ or approximately $125 \mathrm{~km}$ ) and 62 vertical layers up to $5 \mathrm{hPa}$. The Nucleus for European Modelling of the Ocean version 2 was used for the oceanic component (Madec, 2008 ) with an average horizontal resolution of $1^{\circ}$ (approximately $110 \mathrm{~km}$ ) and 42 vertical levels. The sea-ice component was the Louvain-la-Neuve Sea Ice Model (LIM) version 2 (Fichefet and Maqueda, 1997). The Ocean Atmosphere Sea Ice Soil coupler (OASIS) version 3 (Valcke, 2006) was used to couple the atmosphere-land surface module with the ocean-sea ice module.

WAVEWATCH III is a third-generation "phase-averaged" model based on a stochastic representation of the sea sur- 

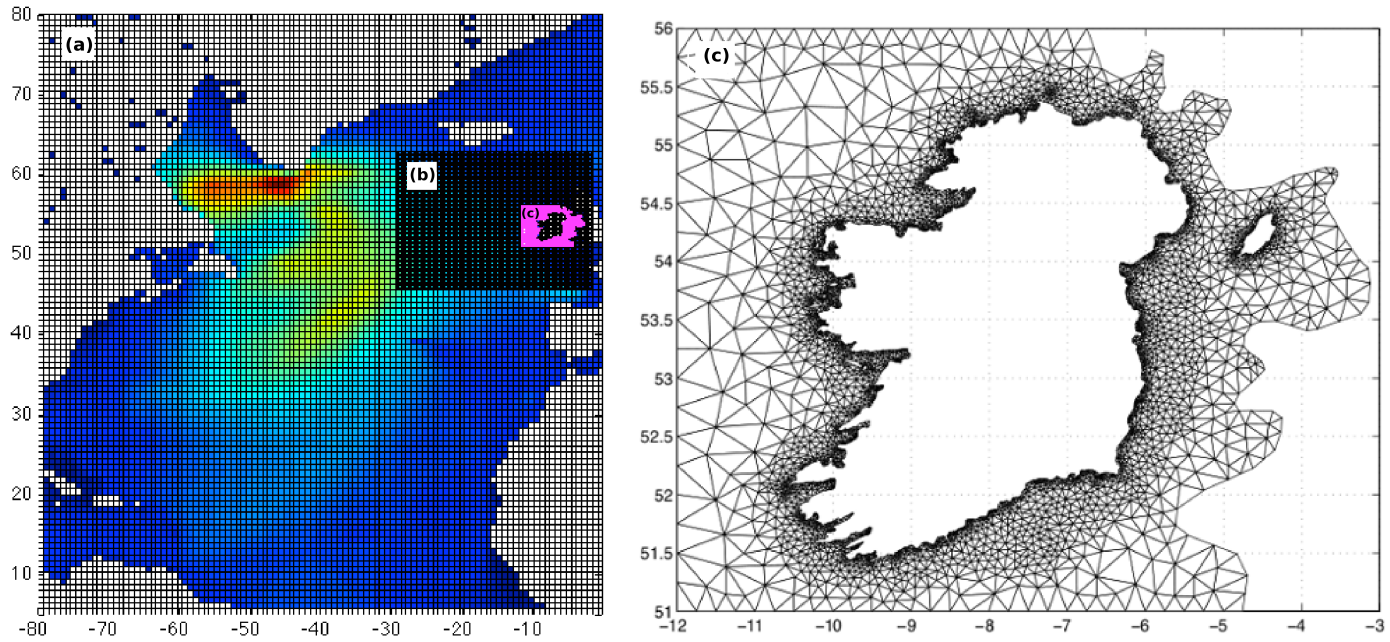

Figure 1. Left panel: the three wave model grids as described in Gallagher et al. (2016a). (a) The largest resolution North Atlantic grid has a $0.75^{\circ} \times 0.75^{\circ}$ resolution. (b) The grid for the Northeast Atlantic has a $0.25^{\circ} \times 0.25^{\circ}$ resolution. (c) The unstructured grid around Ireland has a resolution ranging from $15 \mathrm{~km}$ offshore to $1 \mathrm{~km}$ in the nearshore. Right panel: wave model unstructured grid used for the finest resolution domain around Ireland (c). This grid has 4473 nodes and the resolution varies from $15 \mathrm{~km}$ offshore to $1-2 \mathrm{~km}$ in the nearshore.

face solving the wave-action balance equation (Komen et al., 1996). The evolution of the wave energy spectrum (or variance density spectrum) in the presence of currents and bathymetry is described through the conservation of action density (advection and refraction), which is balanced by source terms (Janssen, 2008). The source terms correspond to physical processes such as the generation of waves by wind, dissipation (white-capping and bottom friction) and nonlinear wave-wave interactions.

The $10 \mathrm{~m}$ wind speeds and sea-ice fields from an ensemble of EC-Earth global climate projections (Gleeson et al., 2013) were used to drive an ensemble of nested regional wave projections over the North Atlantic using the WAVEWATCH III model (see Fig. 1). This was done in order to estimate how climate change might affect the wave climate and wave energy resource around Ireland and the North Atlantic. The outermost WAVEWATCH III grid was a regular grid of $0.75^{\circ} \times 0.75^{\circ}$ resolution over the North Atlantic; the second grid covered part of the Northeast Atlantic on a $0.25^{\circ} \times 0.25^{\circ}$ regular grid and the innermost grid centred around Ireland was unstructured with a resolution of approximately $15 \mathrm{~km}$ at the grid boundaries increasing to $1 \mathrm{~km}$ in the nearshore. The North and Northeast Atlantic grids were twoway nested, whereas the innermost grid was run separately using the wave spectra output from the second grid to force the innermost grid 3 at its boundaries. Grid 3 was constructed using an unstructured grid formulation (Roland, 2008). Further details on this set-up can be found in Gallagher et al. (2016a).

The EC-Earth historical simulations span from 1850 to 2009 and include observed greenhouse gas and aerosol concentrations, including volcanic eruptions. The future simulations ran from 2006 to 2100 where the RCP4.5 and RCP8.5 climate scenarios developed for CMIP5, the Coupled Model Intercomparison Project 5 (Taylor et al., 2012), were applied. To generate the wave datasets, 3 of the 14 EC-Earth ensemble members were used; these were representative of the spread of the EC-Earth ensemble. This is because the EC-Earth ensemble does not have a very large spread in terms of mean annual wind speeds and the three chosen ensemble members cover the range of interannual variability of the winds.

Each member consists of an historical simulation and 2 future simulations (RCP4.5 and RCP8.5) and are denoted mei $X$, me $4 X$ and me $8 X$ where $X=1,2,3$ denotes the ensemble member. WAVEWATCH III simulations were run for the following 30-year periods: 1980-2009 and 2070-2099 for each available EC-Earth ensemble member. The comparisons referred to hereafter are between the future period 2070-2099 and the historical period 1980-2009.

The final dataset used in this study is the monthly observation station-based NAO index by NCAR which was computed using MSLP data recorded in Reykjavik (Iceland) and Ponta Delgada (Azores) and is based on Hurrell (1996). In this case, for each month each station's raw data are normalised separately by the 1864-1983 long term mean; the NAO station index is then the difference between the Reykjavik and Ponta Delgado normalised values.

\section{EC-Earth and WAVEWATCH III validation and projection summary}

A full validation of means and extremes of EC-Earth surface winds and WAVEWATCH III $H_{\mathrm{s}}$ is presented in Gallagher et al. (2016a). The EC-Earth and WAVEWATCH III data capture wind/wave extremes well for the period 1981-2009 compared to ERA-Interim and an ERA-Interim driven wave 
Change in $10 \mathrm{~m}$ wind speed percentiles over the Atlantic (2071-2100) vs. (1980-2009)

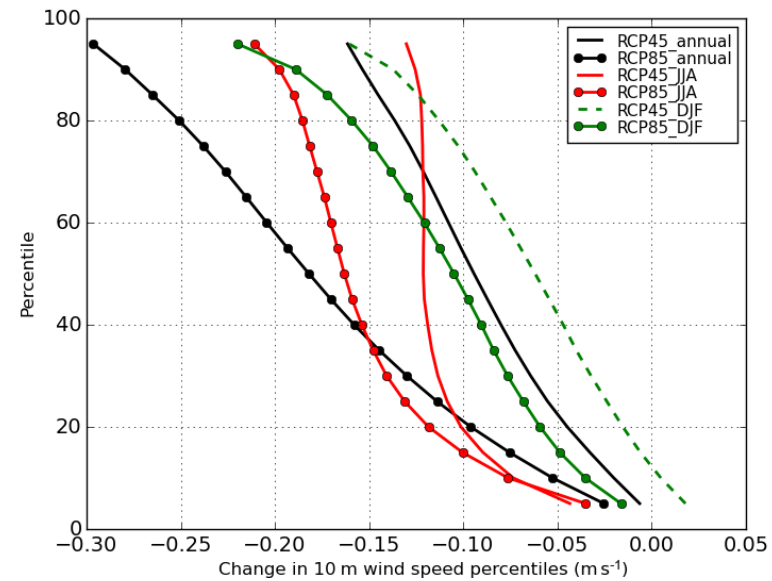

Figure 2. The annual (black), JJA (red, summer) and DJF (green, winter) change in the $10 \mathrm{~m}$ wind speed percentiles over the Atlantic Ocean for the future (2070-2099) versus the historical (1980-2099) period under RCP8.5.

hindcast, which was independently validated using wave data from 11 buoys located around the coast of Ireland.

The EC-Earth RCP4.5 and RCP8.5 projections show an average decrease in mean $10 \mathrm{~m}$ wind speeds over the North Atlantic Ocean for each season, greater under RCP8.5 than RCP4.5 (Gallagher et al., 2016a, b). They also suggest decreases in wind extremes (e.g. a $14 \%$ decrease in the 95th percentile of $10 \mathrm{~m}$ wind speed in winter under RCP8.5, see Fig. 2) and an overall decrease in storminess, defined as depressions with a core pressure $<990 \mathrm{hPa}$ crossing an area around Ireland $\left(50-57^{\circ} \mathrm{N}, 3-13^{\circ} \mathrm{W}\right)$. This is consistent with the decrease in the Arctic to Equator temperature gradient at low levels of the atmosphere. In agreement with the wind projections, the WAVEWATCH III projections show overall decreases in annual and seasonal mean $H_{\mathrm{s}}$ over the North Atlantic by the end of the century (up to $10 \%$ in winter and up to $15 \%$ in summer) and up to $15 \%$ decreases in the 90th and 95th percentiles of $H_{\mathrm{s}}$ (Gallagher et al., 2016a).

Projected changes in the 95th percentile of $H_{\mathrm{s}}$ for winter for each RCP4.5 and RCP8.5 ensemble member are shown in Fig. 3. In this figure (a) shows the ensemble mean $H_{\mathrm{s}}$ for the mei $X$ ensemble members for the period 1980-2009, (b)-(d) show the projected percentage change in the 95th percentile of winter $H_{\mathrm{s}}$ for each me $4 X$ while (e)-(g) show the corresponding changes for each me $8 X$. The ensemble mean $H_{\mathrm{s}}$ for the mei $X$ ensemble members is shown, rather than individual members, and is included in order to give context to the projected changes. The 95th percentile of $H_{\mathrm{s}}$ is projected to decrease in most coastal areas around Ireland. The increase in the 95th percentile of $H_{\mathrm{s}}$ in the Irish Sea for me41 is dubious because the coarse resolution of the EC-Earth simulations $(125 \mathrm{~km})$ is of the same order of magnitude as the extent of the Irish Sea which acts much like a closed basin as regards wave modelling, with local wind-seas dominating the wave climate (Gallagher et al., 2014). The projected decreases off the west coast of Ireland are not statistically significant in me41 and me83 (lack of hatching in these areas in Fig. 3) and indicate that there is still uncertainty in the projections of higher percentiles.

\section{Analysis and results}

\subsection{North Atlantic Oscillation (NAO)}

There are many ways to describe the temporal evolution of the NAO index. The most popular and simplest method involves calculating a station-based NAO index, as discussed in Sect. 2. This method was also applied to the EC-Earth mei $X$ historical simulation data and me $4 X$ and me $8 X$ RCP4.5 and RCP8.5 projection data. As for the observation data monthly indices were computed for each of the three EC-Earth ensembles. Note that the future projection data were normalised using the 1864-1983 data from the corresponding historical simulation. MSLP values at Reykjavik and Ponta Delgado were extracted from the EC-Earth MSLP gridded fields using the nearest neighbour remapping algorithm (remapnn) available in the CDO (Climate Data Operators: Schulzweida et al., 2006) package.

Histograms of the distribution of monthly mean NAO index (using the months of December, January, February and March; DJFM or winter hereafter and chosen because winds are stronger and wave heights are larger during these months) covering 30-year historical/future periods are shown in Fig. 4 where the observed NAO and NAO based on the ECEarth mei $X$ historical simulation are for the period 1980 2009 while the EC-Earth projection data (me $4 X$ and me $8 X$ ) are valid for the period 2070-2099. Each distribution thus comprises of 120 data points. At the $\alpha=0.05$ significance level two-sample Kolmogorov-Smirnov statistical tests on the data suggest that there is no difference between the meil and mei3 NAO distributions and the NAO based on observations other than chance variation but that the mei2 distribution is different. The $p$ value for mei2 is quite close to 0.05 which justifies our inclusion of this ensemble member in the rest of the study. This also provides confidence in using the station-based NAO computed using EC-Earth data, which is only available on a coarse $125 \mathrm{~km}$ grid. The same test, pairing each historical ensemble member mei $X$ with its corresponding me $4 X$ and me $8 X$ distributions, suggests that in all cases except mei3/me43 there are no statistical differences between the distributions at the $\alpha=0.05$ level.

The observed and modelled DFJM station-based NAO indices for the two 30-year periods discussed above were used in the analysis presented in Sects. 4.2 and 4.3 below. 


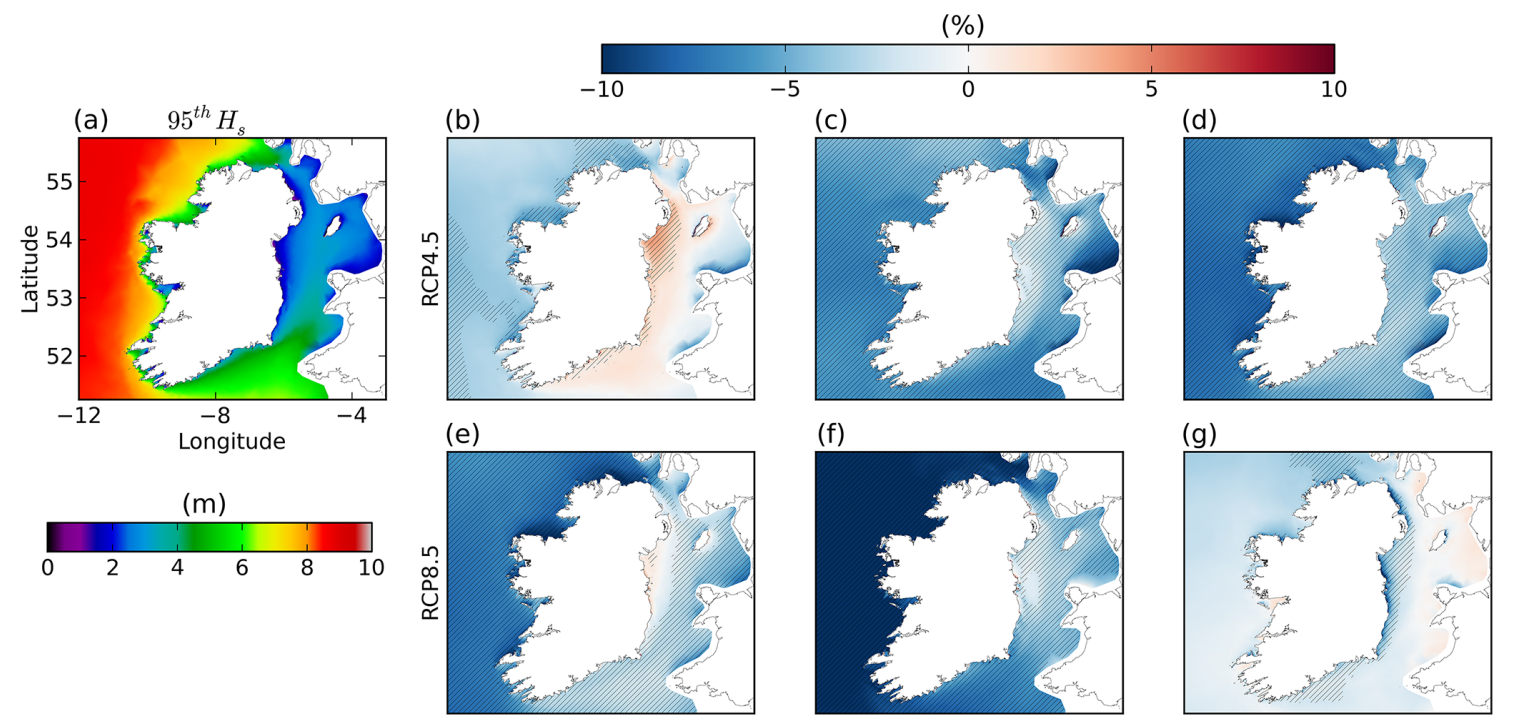

Figure 3. (a) Ensemble mean DJF 95th percentile of $H_{\mathrm{S}}(\mathrm{m})$ for 1980-2009: (b-d) Projected change in the DJF 95th percentile of $H_{\mathrm{S}}$ for 2070-2099 relative to 1980-2009 for me41, me42 and me43. (e)-(g) are similar to (b)-(d) but show me81, me82, me83. Hatching denotes areas where the magnitude of the change exceeds twice the inter-ensemble member standard deviation.
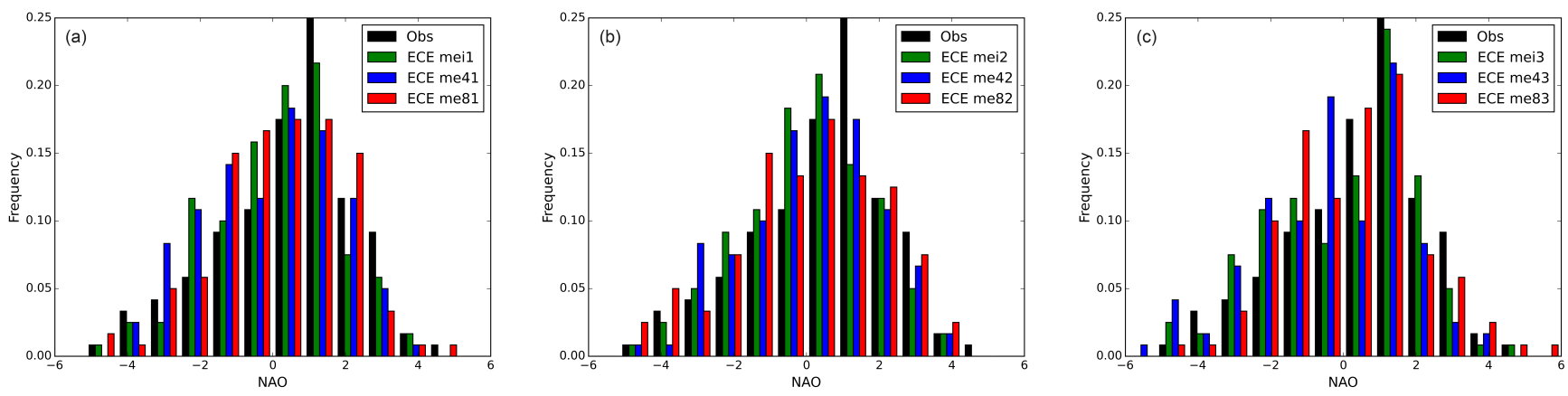

Figure 4. Histogram of the station-based index of NAO for the following cases: (left) observations (1980-2009), EC-Earth mei1 (19802009), EC-Earth me41 (2070-2099), EC-Earth me81 (2070-2099). (centre) shows the same for ensemble number 2 and (right) shows ensemble number 3. In the case of observation-based NAO the months of December to March are included. Similarly, December to March were included for the EC-Earth based calculations where monthly mean MSLP fields were applied.

\subsection{NAO versus $H_{\mathrm{s}}$}

Figure 5 shows the Spearman rank correlation coefficient between the station-based NAO index and the 95th percentile of $H_{\mathrm{S}}$ for DJFM for the historical period (1980 to 2009) and the period 2070-2099 under RCP4.5 and RCP8.5 for each ensemble member. Previous studies have shown a strong correlation between NAO and $H_{\mathrm{S}}$ for the present wave climate off the west coast of Ireland (Gallagher et al., 2014), and for more extreme wave heights in the Northeast Atlantic and North Sea regions (Santo et al., 2016b). This is consistent with Figure $5 \mathrm{a}-\mathrm{c}$ which shows the strong positive correlation coefficient, by ensemble member, between NAO and $H_{\mathrm{s}}$ averaged over the historical period. A strong positive correlation was also found under the RCP4.5 and RCP8.5 scenarios (Fig. 5d-i), slightly stronger under the RCP4.5 scenario.
In general, the correlation increases off the west coast of Ireland under both RCP scenarios relative to the historical period, with the exception of me81, which shows a reduction in correlation south of Ireland. The influence of the NAO loses significance in southern parts of the model domain in each of the ensemble members (historical and future periods), and is strongest to the west and northwest, as can be seen in all panels in Fig. 5. There are large areas to the west and northwest of Ireland showing a correlation coefficient of over +0.7 ( significant at the $\alpha=0.05$ level). Contrary to this, a small area to the east of Scotland shows a negative correlation between NAO and the 95th percentile of $H_{\mathrm{s}}$, present in each of the historical realisations. This may be because this area is close to the WAVEWATCH III domain boundary. Overall, the influence of the NAO on the wave climate of the Northeast At- 
(a)

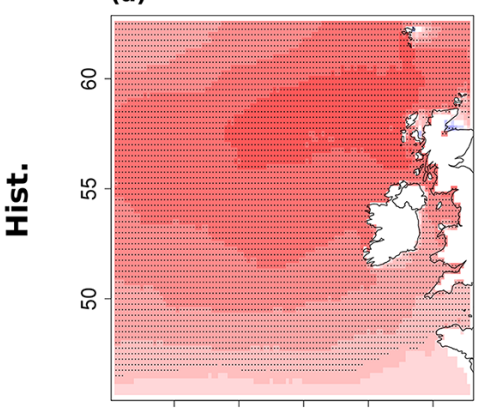

(d)

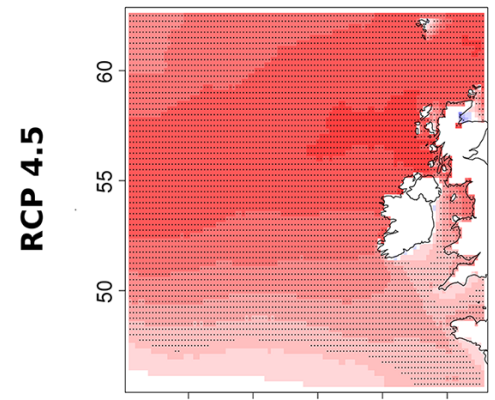

(g)

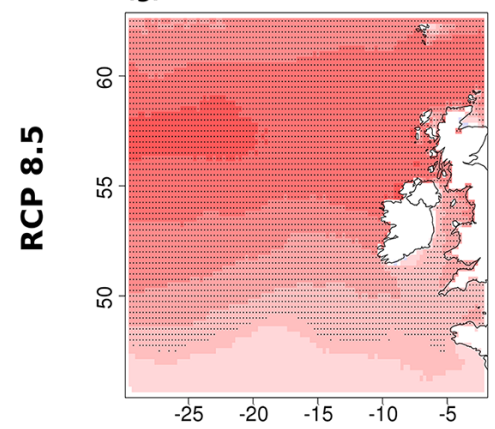

(b)

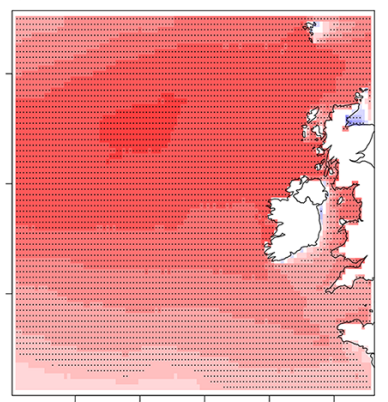

(e)

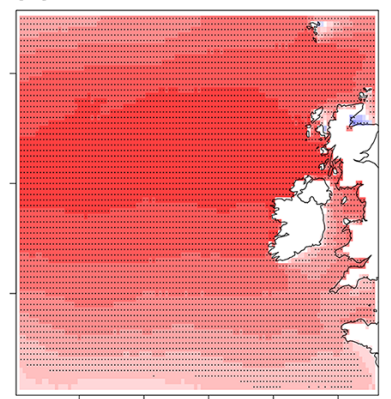

(h)

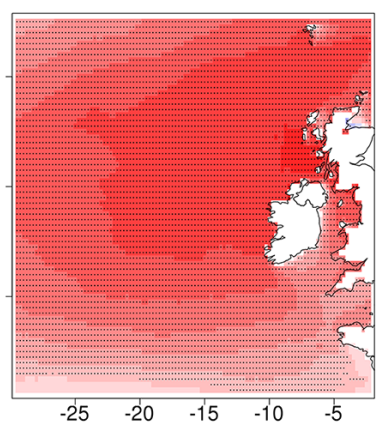

(c)

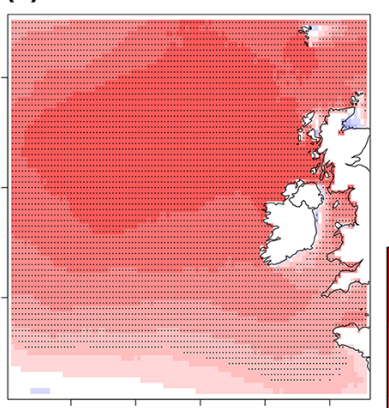

(f)

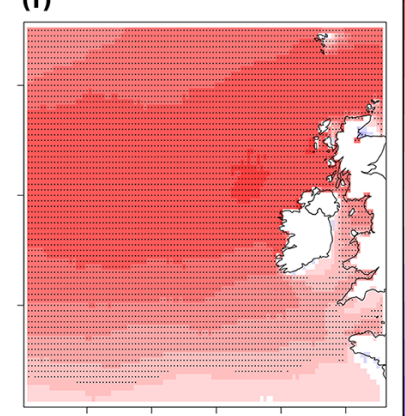

0.5

(i)

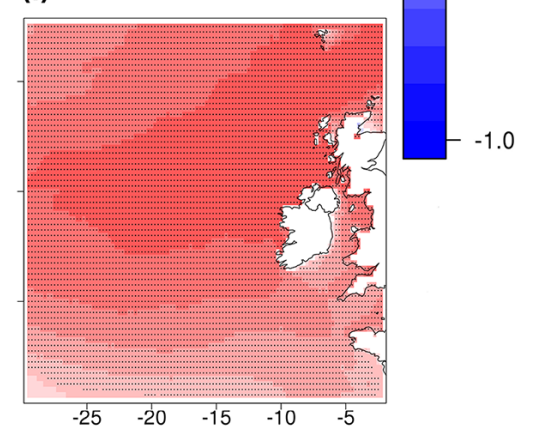

Figure 5. The Spearman correlation coefficient between the NAO index and the 95th percentile of $H_{\mathrm{S}}$ for DJFM. (a-c) historical period (1980-2009) 3 × ensemble members; (d-f) future period 2070-2099 under RCP4.5 and similarly (g-h) is for 2070-2099 under RCP8.5. Correlations statistically significant at the $\alpha<0.05$ level are dotted.

lantic for DJFM is statistically significant. The next Sect. 4.3 deals with extreme winter sea states in relation to the NAO.

\subsection{NAO versus extreme waves}

In this section we examine the effect of the NAO on the most extreme winter sea states, by fitting the Generalised Extreme Value (GEV) distribution to the simulated $H_{\mathrm{s}}$ data on the second grid shown in Fig. 1b covering part of the Northeast Atlantic. The GEV models the maxima of blocks of data; for a full introduction, see Coles (2001). Here we consider monthly maxima of $H_{\mathrm{s}}$ for the DJFM months and fit the GEV using maximum likelihood (ML) inference with the R package ismev (https://CRAN.R-project.org/package=ismev).
The GEV distribution function contains three parameters and is given by

$G(z)=\exp \left(-\left[1+\xi\left(\frac{z-\mu}{\sigma}\right)\right]^{-1 / \xi}\right)$

where $-\infty<\xi<\infty$ is known as the shape, $-\infty<\mu<\infty$ is the location and $\sigma>0$ is the scale. Once the parameters have been fitted to the data, we may invert the distribution to find $N$-year return levels; that is, the value of $H_{\mathrm{S}}$ which we expect to be exceeded once every $N$ years. The approximate normality of the ML estimate can then be used to derive confidence intervals for the return levels (cf. chap. 2 of Coles, 2001, for full discussion of the delta method).

While the theoretical basis for the use of the GEV assumes a stationary distribution, it is common practice to allow some of the parameters to be non-constant. For example, long-term 
NAO $=0$
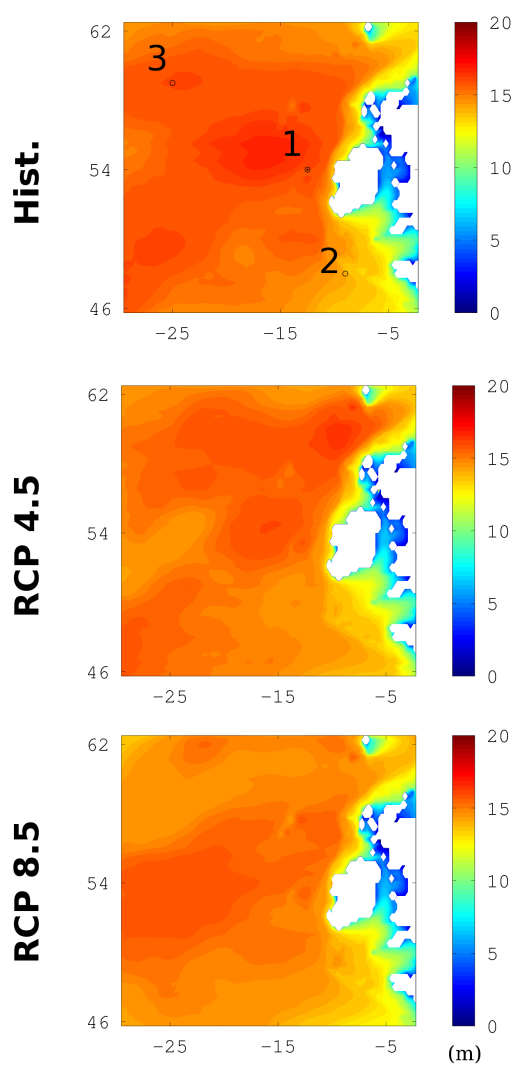

NAO $=+2$
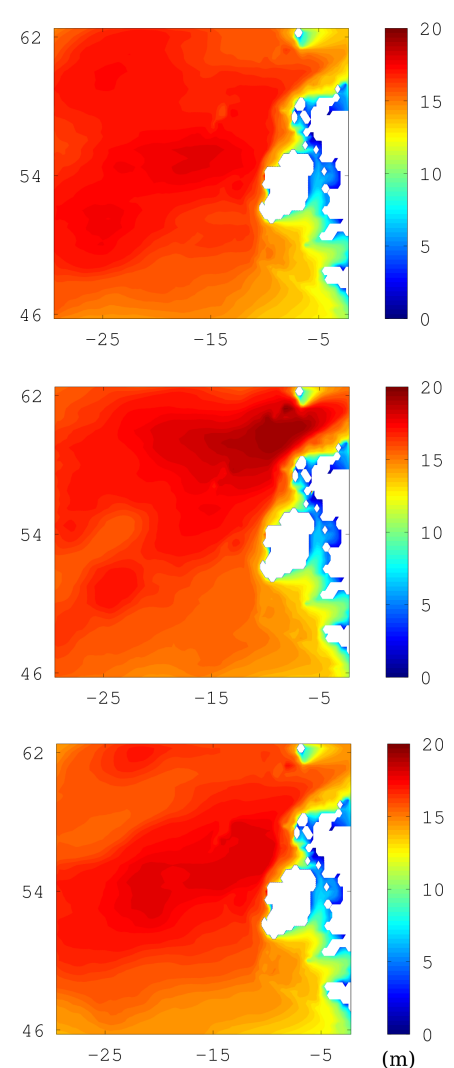

Difference
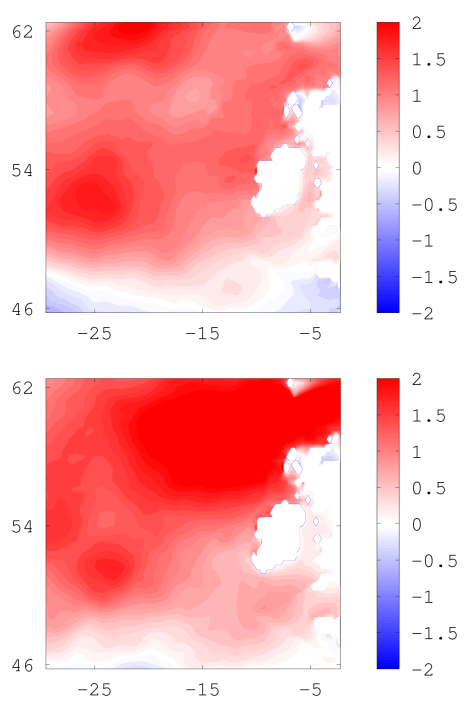

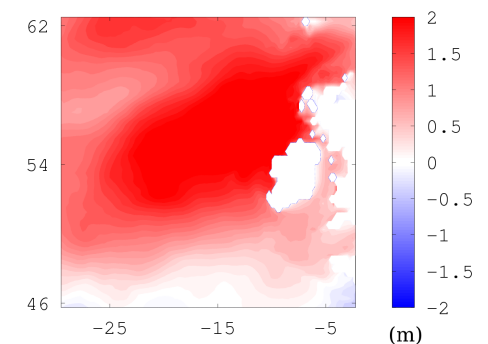

Figure 6. Ensemble means of the 20-year return levels of $H_{\mathrm{S}}$ for the historical hindcast (top) and simulated future scenarios RCP4.5 (middle) and RCP8.5 (bottom). The NAO indices are 0 (left column) and +2 (middle column). The right-hand column shows the differences: $\{\mathrm{NAO}=+2\}-\{\mathrm{NAO}=0\}$.

trends in extremes may be studied by including a linear dependence in time (e.g. Caires et al., 2006) and seasonality effects may also be incorporated (Clancy et al., 2015; Izaguirre et al., 2011). Other covariates may also be included. In Izaguirre et al. (2011), various climate indices were used as linear covariates for the location parameter in order to examine interannual variability of wave extremes.

We adopt a similar, but more general, approach here and include the monthly NAO index as a covariate in both the location and scale parameters. We now have $\mu(t)=\mu_{0}+$ $\mu_{\mathrm{NAO}} \mathrm{NAO}(t)$, where $\mu_{0}$ and $\mu_{\mathrm{NAO}}$ are constants determined by the ML fit to the data. To ensure a positive shape, we reparameterise with $\phi=\log \sigma$ and allow $\phi(t)$ to vary with NAO in the same way as $\mu(t)$. The shape parameter is kept constant throughout. Other relationships and covariates could be explored in future work.

The model outlined above was fitted to each of the three ensemble members in the historical and future scenarios, for the domain covered by the second grid. Return levels are now a function of the NAO index and may be plotted for a given value. To investigate the influence of a positive NAO index on extremes of $H_{\mathrm{S}}$ suggested in the previous section, we choose to compare a neutral $(\mathrm{NAO}=0)$ and medium-strong positive value of 2. In Fig. 6 we present 20-year return levels, showing the historical, RCP4.5 and RCP8.5 ensemble means. The panels on the left of Fig. 6 show the 20-year return levels for an NAO of zero, while the middle panels show the return levels for the positive phase where $\mathrm{NAO}=2$. On the right is the difference between the two.

We first consider the left-hand column, that is, when the NAO index is zero. We find mostly a decrease in return levels in the seas to the west of Ireland for both future scenarios, when compared with the historical. This is consistent with the general decreasing trend found in mean winter sea states in Gallagher et al. (2016a, b) and in Fig. 3 which shows the projected changes for the 95th percentile of $H_{\mathrm{s}}$. However, the middle column in Fig. 6 suggests that the NAO can exert a strong influence and change this pattern. Much like the strongly positive correlation between the NAO and the 95th percentile of $H_{\mathrm{S}}$ shown in Fig. 5, in general we see that the increase in NAO results in an increase in the values of extreme $H_{\mathrm{s}}$, particularly to the west and north-west of Ireland and Scotland. In the historical hindcast (top row of Fig. 6), we see increases due west of Ireland of roughly $0.5 \mathrm{~m}$ to almost 
$2 \mathrm{~m}$. This is broadly consistent with Izaguirre et al. (2011): using satellite data with a much coarser resolution, they report an increase of up to $0.75 \mathrm{~m}$ for each unit of positive NAO in the North East Atlantic.

Much spatial variation can be seen under the climate change scenarios. Under RCP4.5 the NAO influence is strongest to the north-west of Scotland, whereas this occurs further south, closer to the north-west of Ireland, under RCP8.5. From the differences shown in the right-hand column, we find regions in the south of the domain where the NAO exerts little influence and even, particularly in the historical hindcast, where the effect is reversed; i.e. the increased NAO decreases the expected return levels.

Next we focus on three specific locations, with coordinates $\left(12.5^{\circ} \mathrm{W}, 54^{\circ} \mathrm{N}\right),\left(9^{\circ} \mathrm{W}, 48^{\circ} \mathrm{N}\right)$ and $\left(25^{\circ} \mathrm{W}, 59^{\circ} \mathrm{N}\right)$ marked as 1, 2 and 3 in Fig. 6. In Fig. 7 we show the 20 -year return levels of $H_{\mathrm{s}}$ for each as a function of the NAO index, along with the lower and upper bounds of the $95 \%$ confidence intervals for the estimates. Despite some differences between the various locations, the NAO can be seen to have an influence on these winter extremes, with positive phases increasing and negative phases decreasing the 20 -year return levels.

Again, we see clearly that the strength of this influence varies geographically and also between the historical and future scenarios. At the first location at the top of Fig. 7, for example, we find that the extremes are expected to decrease in the future for negative or small positive NAO values. However, in the RCP8.5 scenario, a strong positive phase of the NAO is predicted to amplify the extremes beyond what would have been historically expected. On the other hand, this is not the case at the third location (bottom panel of Fig. 7).

\section{Conclusions}

We analysed time-series of the station-based NAO index computed using an ensemble of global EC-Earth climate projections and the influence of this index on regional wave projections over the North Atlantic. With the exception of me43 no statistically significant changes were found in the distribution of the index derived from projections for the end of the century relative to the historical period 1980-2009.

The 95th percentile of $H_{\mathrm{S}}$ in the Northeast Atlantic is strongly positively correlated to the NAO, with the strongest correlations $(>0.7)$ found to the west and northwest of Ireland. The correlation is generally higher for the future period 2070-2099 under RCP4.5 and RCP8.5 relative to the historical period. For each of the 6 future wave projections $(3 \times \mathrm{RCP} 4.5$ and $3 \times \mathrm{RCP} 8.5$ scenarios), the strong influence of the NAO on the wave climate of Ireland persists to the end of the century.

In order to examine extreme sea states, we fitted a nonstationary Generalised Extreme Value distribution to the
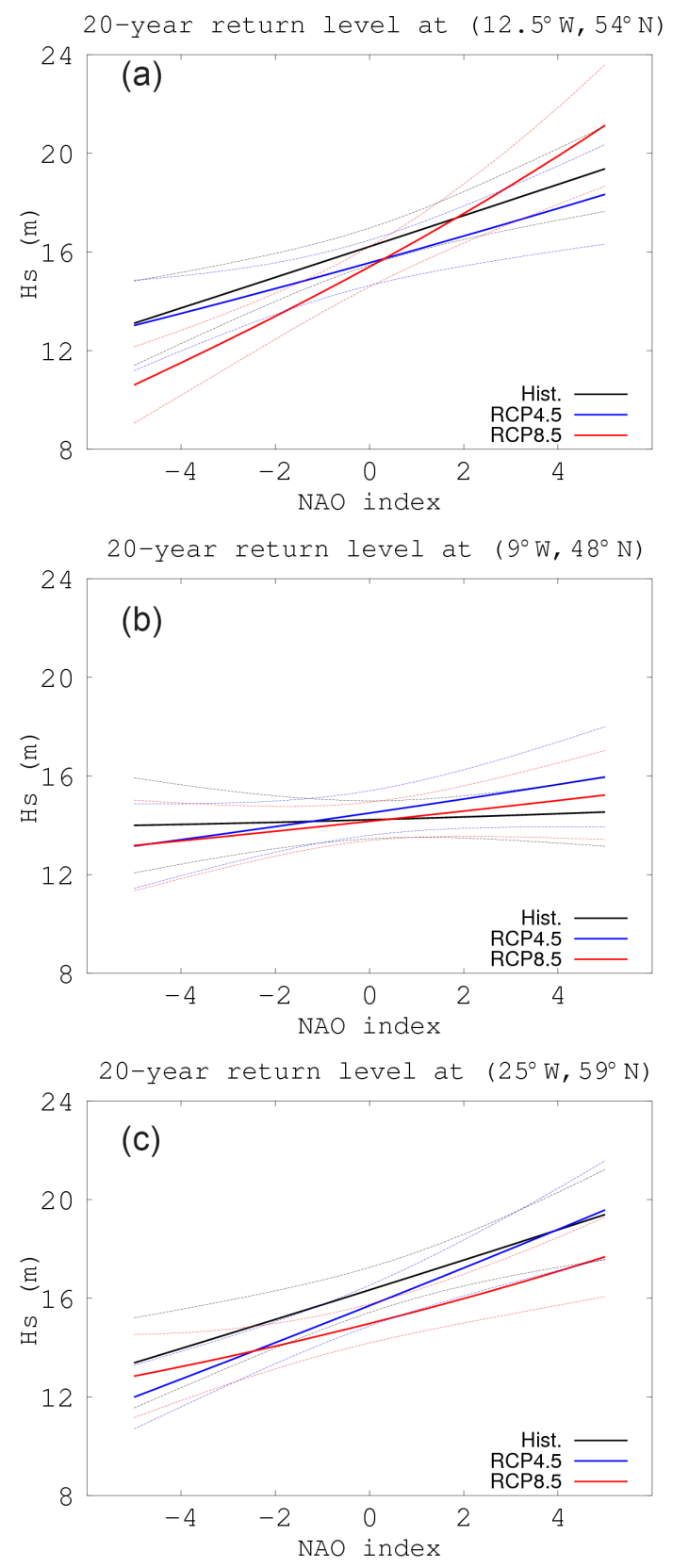

Figure 7. Ensemble mean estimates of the 20-year return levels of $H_{\mathrm{S}}$ (solid curves), along with $95 \%$ confidence intervals (dashed), as functions of NAO index for the three locations indicated in the upper-left panel of Fig. 6. The historical hindcast (black) is shown along with the two future projections (blue and red).

datasets. The resulting 20-year return levels of $H_{\mathrm{S}}$ show an important influence from the NAO covariate. During periods of neutral NAO index, we may expect future extremes to be reduced when compared with the historical period. However, there may be a strong enhancement of extremes by the NAO, with high positive values of the index leading to higher winter return levels. This amplification shows a significant spa- 
tial variation, with a much stronger effect seen, for example, to the north-west of Scotland. This suggests a possible future extension of this work with the use of a more sophisticated spatial model of extremes (e.g. Clancy et al., 2016).

The work can be further expanded by generating a larger multimodel (both in terms of the forcings and the wave model) ensemble and an ensemble of higher resolution e.g. using CMIP6 simulation data. Recent studies, for example by Wang et al. (2015), have shown that for projections in $H_{\mathrm{s}}$ different climate models can simulate significantly different responses to the RCP4.5 and RCP8.5 scenarios. Moreover, the intermodel uncertainty can be much greater than that of the RCP scenario responses. This demonstrates the need for a multimodel approach in the future. Any further assessment of the future wave climate of Ireland should be expanded to use a coupled atmosphere-wave-ocean numerical model to capture atmospheric and wave-current interactions on extreme sea states. A better understanding of storm track dynamics is also needed in order to improve future models, and hence wave climate projections. A wide range of teleconnection patterns could also be investigated, as well as investigating the influence of the definition of the teleconnections (e.g. station-based versus PCA definition of the NAO) on the results.

\section{Data availability}

The datasets have been archived at Met Éireann. There is currently no publicly available method for data access so the Met Éireann should be contacted for dataset access.

Author contributions. Emily Gleeson ran the EC-Earth global climate simulations, analysed the wind outputs and the NAO computed from EC-Earth data; Sarah Gallagher ran the WAVEWATCH III simulations using EC-Earth boundary conditions, analysed the wave outputs and correlations between significant wave height and the NAO; Colm Clancy did a statistical analysis of extreme waves and the NAO using a Generalised Extreme Value distribution. Emily Gleeson, Sarah Gallagher and Colm Clancy prepared the manuscript with contributions from Frédéric Dias.

Competing interests. The authors declare that they have no conflict of interest.

Acknowledgements. The authors are grateful to John O'Sullivan for helpful discussions on extreme value statistics. The authors also wish to acknowledge Roxana Tiron who helped to run the wave simulations. The numerical simulations were performed on the Fionn cluster at the Irish Centre for High-end Computing (ICHEC) and at the Swiss National Computing Centre under the PRACE-2IP project (FP7 RI-283493) "Nearshore wave climate analysis of the west coast of Ireland". Thank you also to both reviewers for their useful comments which have helped to improve the paper.
Edited by: S. Carniel

Reviewed by: L. O'Brien and one anonymous referee

\section{References}

Atan, R., Goggins, J., and Nash, S.: A Detailed Assessment of the Wave Energy Resource at the Atlantic Marine Energy Test Site, Energies, 9, 967, 2016.

Barnston, A. and Livezey, E.: Classification, seasonality and persistence of low-frequency atmospheric circulation patterns, Mon. Weather Rev., 115, 1083-1126, 1987.

Bertin, X., Prouteau, E., and Letetrel, C.: A significant increase in waveheight in the North Atlantic Ocean over the 29th century, Global Planet. Change, 106, 77-83, 2013.

Caires, S., Swail, V. R., and Wang, X. L.: Projection and analysis of extreme wave climate, J. Climate, 19, 5581-5605, 2006.

Charles, E., Idier, D., Thiébot, J., Le Cozannet, G., Pedreros, R., Ardhuin, F., and Planton, S.: Present Wave Climate in the Bay if Biscay: Spatiotemporal Variability and Trends from 1958 to 2001, J. Climate, 25, 2020-2039, 2012.

Church, J., Clark, P., Cazenave, A., Gregory, J., Jevrejeva, S., Levermann, A., Merrifield, M., Milne, G., Nerem, R., Nunn, P., Payne, A., Pfeffer, W., Stammer, D., and Unnikrishnan, A.: Sea Level Change, book section 13, 1137-1216, Cambridge University Press, Cambridge, United Kingdom and New York, NY, USA, doi:10.1017/CBO9781107415324.026, 2013.

Clancy, C., Belissen V, Tiron, R., Gallagher, S., and Dias, F.: Spatial variability of extreme sea states on the Irish west coast, in: Proceedings of the ASME 2015 34th International Conference on Ocean, Offshore and Arctic Engineering, St John's, NL, Canada, 2015.

Clancy, C., O’Sullivan, J., Sweeney, C., Dias, F., and Parnell, A. C.: Spatial Bayesian hierarchical modelling of extreme sea states, Ocean Model., 107, 1-13, 2016.

Coles, S.: An introduction to statistical modeling of extreme values, Springer-Verlag London, 2001.

Colle, B. A., Zhang, Z., Lombardo, K. A., Chang, E., Liu, P., and Zhang, M.: Historical evaluation and future prediction of eastern North American and western Atlantic extratropical cyclones in the CMIP5 models during the cool season, J. Climate, 26, 68826903, 2013.

Dodet, G., Bertin, X., and Taborda, R.: Wave climate variability in the North-East Atlantic Ocean over the last six decades, Ocean Model., 31, 120-131, 2010.

Dommenget, D. and Latif, M.: A cautionary note on the interpretation of EOFs, J. Climate, 15, 216-225, 2002.

Fichefet, T. and Maqueda, M.: Sensitivity of a global sea ice model to the treatment of ice thermodynamics and dynamics, J. Geophys. Res.-Oceans, 102, 12609-12646, 1997.

Gallagher, S., Tiron, R., and Dias, F.: A detailed investigation of the nearshore wave climate and the nearshore wave energy resource on the west coast of Ireland, in: Proceedings of the ASME 2013 32nd International Conference on Ocean, Offshore and Arctic Engineering OMAE, American Society of Mechanical Engineers, Nantes, France, doi:10.1115/OMAE2013-10719, 2013.

Gallagher, S., Tiron, R., and Dias, F.: A long-term nearshore wave hindcast for Ireland: Atlantic and Irish Sea coasts (1979-2012), Ocean Dynam., 64, 1163-1180, doi:10.1007/s10236-014-07283, 2014. 
Gallagher, S., Gleeson, E., Tiron, R., McGrath, R., and Dias, F.: Wave climate projections for Ireland for the end of the 21st century including analysis of EC-Earth winds over the North Atlantic Ocean, Int. J. Climatol., 36, 4592-4607, doi:10.1002/joc.4656, 2016a.

Gallagher, S., Gleeson, E., Tiron, R., McGrath, R., and Dias, F.: Twenty-first century wave climate projections for Ireland and surface winds in the North Atlantic Ocean, Adv. Sci. Res., 13, 75-80, doi:10.5194/asr-13-75-2016, 2016b.

Gallagher, S., Tiron, R., Whelan, E., Gleeson, E., Dias, F., and McGrath, R.: The nearshore wind and wave energy potential of Ireland: A high resolution assessment of availability and accessibility, Renew. Energ., 88, 494-516, doi:10.1016/j.renene.2015.11.010, 2016c.

Gleeson, E., McGrath, R., and Treanor, M.: Ireland's climate: the road ahead, Met Éireann, Dublin, Ireland, 2013.

Greatbatch, R. J.: The North Atlantic Oscillation, Stoch. Env. Res. Risk A., 14, 213-242, 2000.

Hameed, S. and Piontkovski, S.: The dominant influence of the Icelandic Low on the position of the Gulf Stream northwall, Geophys. Res. Lett., 31, L09303, doi:10.1029/2004GL019561 2004.

Hazeleger, W., Severijns, C., Semmler, T., Ştefănescu, S., Yang, S., Wang, X., Wyser, K., Dutra, E., Baldasano, J., Bintanja, R., Bougeault, P., Caballero, R., Ekman, A. M. L., Christensen, J. H., van den Hurk, B., Jimenez, P., Jones, C., Kållberg, P., Koenigk, T., McGrath, R., Miranda, P., Van Noije, T., Palmer, T., Parodi, J., Schmith, T., Selten, F., Storelvmo, T., Sterl, A., Tapamo, H., Vancoppenolle, M., Viterbo, P., and Willén, U.: EC-Earth: A Seamless Earth-System Prediction Approach in Action, B. Am. Meteorol. Soc., 91, 1357-1363, doi:10.1175/2010BAMS2877.1, 2010.

Hazeleger, W., Wang, X., Severijns, C., Ştefănescu, S., Bintanja, R., Sterl, A., Wyser, K., Semmler, T., Yang, S., van den Hurk, B., van Noije, T., van der Linden, E., and van der Wiel, K.: EC-Earth V2.2: description and validation of a new seamless earth system prediction model, Clim. Dynam., 39, 2611-2629, doi:10.1007/s00382-011-1228-5, 2012.

Hurrell, J.: Decadal trends in the North Atlantic Oscillation: regional temperatures and precipitation, Science, 269, 676-679, doi:10.1126/science.269.5224.676, 1996.

Izaguirre, C., Méndez, F. J., Menéndez, M., and Losada, I. J.: Global extreme wave height variability based on satellite data, Geophys. Res. Lett., 38, 1-6, 2011.

Janssen, P. A.: Progress in ocean wave forecasting, J. Comput. Phys., 227, 3572-3594, 2008.

Komen, G. J., Cavaleri, L., Donelan, M., Hasselmann, K., Hasselmann, S., and Janssen, P.: Dynamics and modelling of ocean waves, Cambridge University Press, 1996.

Le Cozannet, G., Lecacheux, S., Delvallee, E., Desramaut, N., Oliveros, C., and Pedreros, R.: Teleconnection pattern influence on sea-wave climate in the Bay of Biscay, J. Climate, 24, 641-652, 2011.

Madec, G.: Nemo ocean engine: Note du pole de modélisation, Institut Pierre-Simon Laplace (IPSL), France, No 27, ISSN: 12881619, 2008.

O'Brien, L., Dudley, J. M., and Dias, F.: Extreme wave events in Ireland: 14680 BP-2012, Nat. Hazards Earth Syst. Sci., 13, 625648, doi:10.5194/nhess-13-625-2013, 2013.
Pokorná, L. and Huth, R.: Climate impacts of the NAO are sensitive to how the NAO is defined, Theor. Appl. Climatol., 119, 639652, 2015.

Roland, A.: Development of WWM II: Spectral wave modelling on unstructured meshes, Ph.D. thesis, Institute of Hydraulics and Wave Resource Engineering, Technical University Darmstadt, Germany, 2008.

Santo, H., Taylor, P., Taylor, R. E., and Stansby, P.: Decadal variability of wave power production in the North-East Atlantic and North Sea for the M4 machine, Renew. Energ., 91, 442-450, doi:10.1016/j.renene.2016.01.086, 2016a.

Santo, H., Taylor, P. H., and Gibson, R.: Decadal variability of extreme wave height representing storm severity in the northeast Atlantic and North Sea since the foundation of the Royal Society, Proc. R. Soc. A, 472, 20160376, doi:10.1098/rspa.2016.0376, 2016b.

Scherrer, S. C., Croci-Maspoli, M., Schwierz, C., and Appenzeller, C.: Two-dimensional indices of atmospheric blocking and their statistical relationship with winter climate patterns in the EuroAtlantic region, Int. J. Climatol., 26, 233-250, 2006.

Schulzweida, U., Kornblueh, L., and Quast, R.: CDO user's guide, Climate Data Operators, Version, 1, 2006.

Taylor, K., Stouffer, R., and Meehl, G.: An Overview of CMIP5 and the Experiment Design, B. Am. Meteorol. Soc., 93, 485498, doi:10.1175/BAMS-D-11-00094.1, 2012.

Tiron, R., Gallagher, S., Gleeson, E., Dias, F., and McGrath, R.: The Future Wave Climate of Ireland: From Averages to Extremes, Procedia IUTAM, 17, 40-46, doi:10.1016/j.piutam.2015.06.007, 2015.

Tolman, H.: User manual and system documentation of Wavewatch III version 4.18, Tech. Rep. 316, NOAA/NWS/NCEP/MMAB, 2014.

Ulbrich, U., Leckebusch, G., and Pinto, J. G.: Extra-tropical cyclones in the present and future climate: a review, Theor. Appl. Climatol., 96, 117-131, 2009.

Uppala, S. M., Kållberg, P., Simmons, A., Andrae, U., Bechtold, V. D., Fiorino, M., Gibson, J., Haseler, J., Hernandez, A., Kelly, G. A., Li, X., Onogi, K., Saarinen, S., Sokka, N., Allan, R. P., Andersson, E., Arpe, K., Balmaseda, M. A., Beljaars, A. C. M., Van De Berg, L., Bidlot, J., Bormann, N., Caires, S., Chevallier, F., Dethof, A., Dragosavac, M., Fisher, M., Fuentes, M., Hagemann, S, Hólm, E., Hoskins, B. J., Isaksen, L., Janssen, P. A. E. M., Jenne, R., McNally, A. P., Mahfouf, J. F., Morcrette, J.-J., Rayner, N. A., Saunders, R. W., Simon, P., Sterl, A., Trenberth, K. E., Untch, A., Vasiljevic, D., Viterbo, P., and Woollen, J.: The ERA-40 re-analysis, Q. J. Roy. Meteor. Soc., 131, 2961-3012, 2005.

Valcke, S.: OASIS3 user guide (prism_2-5), PRISM support initiative report, 3, 64, Technical report, PRISM Support Initiative Report, CERFACS, Toulouse, France, 2006.

van Loon, H. and Rogers, J. C.: The seesaw in winter temperatures between Greenland and northern Europe. Part I: General description, Mon. Weather Rev., 106, 296-310, 1978.

Wang, X. and Swail, V.: Changes of extreme wave heights in Northern Hemisphere oceans and related atmospheric circulation regimes, J. Climate, 14, 2204-2221, 2001.

Wang, X. and Swail, V.: Trends of Atlantic wave extremes as simulated in a 40-year wave hindcast using kinematically reanalysed wind fields, J. Climate, 15, 1020-1035, 2002. 
Wang, X. L., Feng, Y., and Swail, V. R.: Climate change signal and uncertainty in CMIP5-based projections of global ocean surface wave heights, J. Geophys. Res.-Oceans, 120, 3859-3871, doi:10.1002/2015JC010699, 2015.

Woollings, T., Gregory, J. M., Pinto, J. G., Reyers, M., and Brayshaw, D. J.: Response of the North Atlantic storm track to climate change shaped by ocean-atmosphere coupling, Nat. Geosci., 5, 313-317, 2012.
Zappa, G., Shaffrey, L. C., Hodges, K. I., Sansom, P. G., and Stephenson, D. B.: A multimodel assessment of future projections of North Atlantic and European extratropical cyclones in the CMIP5 climate models, J. Climate, 26, 5846-5862, 2013. 